\title{
Prevalence of vacA, cagA, and iceA Virulence Factors of Helicobacter Pylori Isolated from Gastro-duodenal Patients
}

\author{
Ahmed Husham Salman Aumed Arshad Hawezy* \\ Department of Anesthesia / Erbil Technical Medical Institute / Erbil Polytechnic University \\ * Department of Pharmacy / Erbil Technical Medical Institute / Erbil Polytechnic University \\ E-mail: ahmed.selman@epu.edu.iq
}

\begin{abstract}
Back ground: Helicobacter pylori are bacteria colonize in the human epithelial cells of the gastrointestinal tract. Its infection causes different diseases, including chronic gastritis, peptic ulcers, gastric lymphoma and adenocarcinoma. $\mathrm{H}$. pylori have many virulence factors attributing in one or more biological functions.

Objective: Detecting the prevalence of virulence factor genes vacA, cagA, iceA among strain of $H$. pylori using molecular technique (PCR).

Materials and methods: Sixty patients (27 male and 33 female), aged 18 and above included in the present study who showed signs and symptoms of $\mathrm{H}$. pylori, and undergo endoscopy between period of November 2019 and February 2020. RUT and PCR test done to detect the presence of $\mathrm{H}$. pylori infection, also PCR used to detect the three virulence factors.

Results: Result showed that 44 patients, $21(47.7 \%)$ male and $23(52.3 \%)$ female were detected as positive $H$. pylori infections, among them $13(29.5 \%)$ above 50 years, and $31(70.4 \%)$ were below 50 years. While prevalence of the virulence factors vacA, cagA, and iceA were $(100 \%),(84.1 \%)$, and (34.1\%) respectively.

Conclusion: It can be concluded that the frequency and prevalence of these genes are differed and showed significant differences among them. Also, PCR test is sensitive and accurate for detection of $\boldsymbol{H}$. pylori virulence genes.
\end{abstract}

Keywords: Helicobacter pylori, Virulence Factors, CagA, VacA, IceA, PCR.

\section{Introduction}

$H$. pylori is a usually spiral-shaped, gram-negative bacterium, its length is 2 to $4 \mu \mathrm{m}$ and 0.5 to $1 \mu \mathrm{m}$ in width with lophotrichous flagella $(1,2) . H$. pylori's prevalence shows large geographical variations worldwide $(3,4)$. H. pylori infection causes peptic ulcer, chronic gastritis, mucosa-associated lymphoid tissue lymphoma, and gastric carcinoma $(5,6) . H$. pylori have different virulence factors that perform different biological functions, some virulence factors have subtypes also $(7,8)$. The virulence factors of $H$. pylori can be categorized to three major pathogenic processes, including colonization, immune escape, and disease induction $(5,9)$.

Vacuolating cytotoxin a $(V a c A)$ is a cytotoxin that secreted from H. Pylori as a large polypeptide, and before delivering to the host cells as an active form it must be modified by trimming its both ends to be able to exerts its activity $(10,11)$. It performs biological functions like: phagocytosis suppression, inducing tolerogenic dendritic cell, and blocking of effector T-cell response. In addition, vacA has an important role for colonization of H. pylori in vivo. $(5,9)$. All $\mathrm{H}$. pylori strains have the gene that encode vacA, although the cytotoxic activity of the toxin varies among strains by displaying allelic diversity in three main regions of the gene which are the s (signal), the $\mathrm{i}$ (intermediate), and the $\mathrm{m}$ (middle) regions (12).

Cytotoxin-associated gene a $(\mathrm{CagA})$ is one of the most important virulence factors of the $\mathrm{H}$. pylori that have many biological functions including: phagocytosis suppression, decreasing antimicrobial peptide, inducing tolerogenic dendritic cell, and blockingof effector T-cell response (9). Beside those functions, cag A also related to other diseases and consequence, it could have a relation even with infertility in men (13). Not all strain of $\mathrm{H}$. pylori have $\mathrm{CagA}$ virulence factor, strains can be divided into two types, those who have this virulence factor considered as $\operatorname{CagA}$ positive, while those who lack it are $\operatorname{CagA}$ negative strains. The 
geographical distribution differs for these strains, in Western countries, approximately $60 \%$ of $\mathrm{H}$. pylori strains carry CagA, while in East Asian, almost all of the isolates are CagA positive $(14,15)$.

Induced by Contact with Epithelium (iceA) gene was identified when investigating genes "induced by contact of H. pylori with epithelium" in 1998 (9). There is an association between the presence of iceA and peptic ulcer disease (PUD), also, iceA is related with other clinical outcomes in the host, like acute antral inflammation and enhancing the expression of mucosal interleukin (IL-8) $(8,16)$.

Different diagnostic methods used to detect $H$. pylori infection. Among them, PCR test show a high accuracy in detecting $H$. pylori and genes of virulence factors. PCR has superiority on other diagnostic methods as it is simple, rapid and it is very accurate in detecting different genes and their mutations $(5,17)$. In Iraq there is little attention about the genotyping of $H$. pylori isolate therefore this study aimed to detect $h$. pylori using PCR test, and to identify the prevalence of $H$. pylori vacA, cagA, and iceA virulence factors among gastrointestinal patients from Erbil city.

\section{Materials and Methods \\ Sample collection}

The present study included 60 samples that collected at Rizgary Teaching Hospital defectively at Hawler Gastroenterology and Hepatology Center. Samples collected from period of November 2019 and February 2020. Patients included 27 male, 33 female aged 18 and above. All samples collected from patients who submitted to endoscopy procedure. Patients followed instruction before taking biopsy samples like elimination of food and drug taking a day before the procedure. Two samples of $0.5 \mathrm{~cm}$ of the biopsy collected in two different tubes, The first tube used for RUT, while the second tube that contain Dulbecco's phosphate-buffered saline (DPBS) used for PCR test.

\section{DNA extraction}

Genomic DNA extracted directly from biopsy samples using the Presto ${ }^{\mathrm{TM}}$ Mini gDNA Bacteria Kit following the manufacturer's instructions; $100 \mu \mathrm{L}$ elution buffer was used for extracting. Extracted genomics was stored at $-20{ }^{\circ} \mathrm{C}$ before running PCR (18).

\section{Estimation of Extracted DNA}

Before PCR run, agarose gel electrophoresis used to estimate the extracted genomic matter of H. pylori. In which $1 \%$ agarose gel used and run on $85 \mathrm{~V}$ for $45 \mathrm{~min}$.

\section{Polymerase chain reaction (PCR) \\ Primers}

In the present study five sets of primers were used. The first primer 16s rRNA used to detect the genome of $\mathrm{H}$. pylori. The other four primers used to detect genes of virulence factors (vagA, cagA, and iceA). All primers sequences and the size of product are listed in Table (1):

Table (1): the six primers used in present study

\begin{tabular}{|c|c|c|}
\hline Primers & Sequence of the primers ( 5 ' to 3') & $\begin{array}{c}\text { Size of the product by base } \\
\text { pairs }\end{array}$ \\
\hline \multirow{2}{*}{$\operatorname{CagA}$} & $\begin{array}{ll}\text { Forward: } & \text { TGCTAAATTAGACAATTGAGCGA }\end{array}$ & \multirow{2}{*}{290 bp. } \\
\hline & Reverse: $\quad$ AATAATCAACAAACATCACGCCT & \\
\hline \multirow{2}{*}{ VacA } & Forward: $\quad$ GCGGTATCAATCTGTCCAATCA & \multirow{2}{*}{$68 \mathrm{bp}}$. \\
\hline & TGATATTCCCGGTTAGATTTTCCA & \\
\hline \multirow{2}{*}{ iceA } & GACAAGCGGTTGGAGTTTGC & \multirow{2}{*}{851 bp. } \\
\hline & GAGATCATGGCCTACAACCG & \\
\hline \multirow{2}{*}{$16 s \mathrm{rRNA}$} & ACTCCCTACGGGGGAAAGAT & \multirow{2}{*}{$141 \mathrm{bp}}$. \\
\hline & GGACCGTGTCTCAGTTCCAG & \\
\hline
\end{tabular}




\section{PCR run and condition}

Selected genes were amplified using DNA amplification with some optimization, cycling was carried out (Gradient thermal cycler Alpha Cycler PCRmax series). The primers used for PCR were specific for the detection of H. pylori DNA and the four virulence factors (see Table1). Mixture total of $25 \mu$ l used for each primer in $0.5 \mathrm{ml}$ microcentrifuge tube containing: $12.5 \mu 1$ master mix, $2.5 \mu \mathrm{l}$ forward primer, $2.5 \mu 1$ reverse primer, $3 \mu 1$ of the extracted genome, the volume completed to $25 \mu 1$ by adding $4.5 \mu 1$ of free nuclease water (19).

PCR condition and cycling were same for amplification of all the primers, in which started with initial denaturation $95^{\circ} \mathrm{C}$ for 5 minute followed by 45 cycles of denaturation $95^{\circ} \mathrm{C}$ for 40 second, annealing $59^{\circ} \mathrm{C}$ for 45 second, extension $72^{\circ} \mathrm{C}$ for 40 second, and followed by final extension $72^{\circ} \mathrm{C}$ for 5 minute.

\section{Gel electrophoresis}

After running the PCR for each sample using each primer separately, gel electrophoresis done for each sample to observe the results of the amplification, put in the tank and filled with TAE buffer, then add $6 \mu 1$ of the PCR product to each well (note: no need to add loading dye because the master mix already contain it in their component). After loading the samples, the tank cover placed and the electric pole wires (+ and poles) of the electrophoresis gel apparatus connected to its specific places. Power supply of 45 volts was applied for 10 minutes until the DNA left the wells and moved toward the positive electrical side, then the voltage increased to $75 \mathrm{v} / 45 \mathrm{~min}$. Results of amplified DNA bands were visualized by UV-light illuminator at $(240,366 \mathrm{~nm})$ wave length. Pictures of the gel documented using 16MPX camera photography.

\section{Statistical analysis of the results}

Chi-square and Fisher's exact test used to analyze the results of the present study with $(\mathrm{P}<0.05)$ for significant differences.

\section{Results}

Gastric biopsies of sixty patients were analyzed, in which 44 samples showed positive results for $h$. pylori infection, 21 (47.7\%) male and 23 (52.3\%) female. Participant ages varied from 18 to 71 years, in which 13 of them were 50 years or older. Results of all participants regarding to gender and age are shown in Table (2).

Table (2): The age and gender of the 44 positive $H$. pylori patients approved by PCR test in the present study

\begin{tabular}{|c|c|c|}
\hline Variable & Number $(\boldsymbol{n})$. & Percentage \% \\
\hline Gender $(\boldsymbol{n}=44)$ & 21 & 47.7 \\
Male & 23 & 52.3 \\
\hline female & \multicolumn{2}{|l}{} \\
\hline Age $(\boldsymbol{n}=44)$ & 13 & 29.5 \\
Below 50 years 50 years & 31 & 70.5 \\
\hline
\end{tabular}

Regarding results of PCR test using 16srRNA for detecting the presence of $h$. pylori genome among 60 biopsy samples showed 44 (73.3\%) as positive, and 16 (26.7\%) as negative, as shown in Figure (1). 


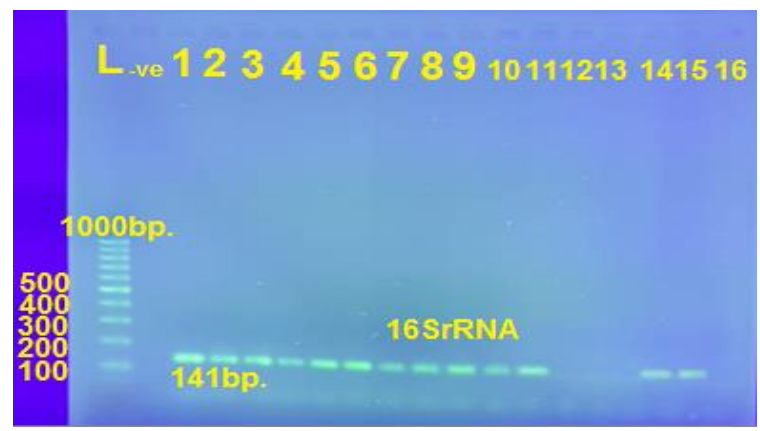

Figure (1): Agarose gel electrophoresis analysis 1\% (stained with safe stain) of PCR products presenting partial specific primer (16srRNA) that showed the expected size 141 bp. Lane L: is 100 bp DNA Marker; Lane 2 is (-ve) negative control, Lanes 3-16: samples amplified from $h$. pylori genome run on $75 \mathrm{~V}$ for $45 \mathrm{~min}$. samples number 1 to10, 14, and 15 were positive for H.pylori infection, while samples number 12, 13 and 16 were negative.

Results of PCR test using specific primer to detect vacA gene among 44 positive $h$. pylori, showed 44 (100\%) positive, as shown in Figure (2). PCR test for cagA gene showed $37(84.1 \%)$ positive results, as shown in Figure (3). And finally, PCR test for iceA gene showed 15 (34.1\%) positive results, as shown in Figure (4).

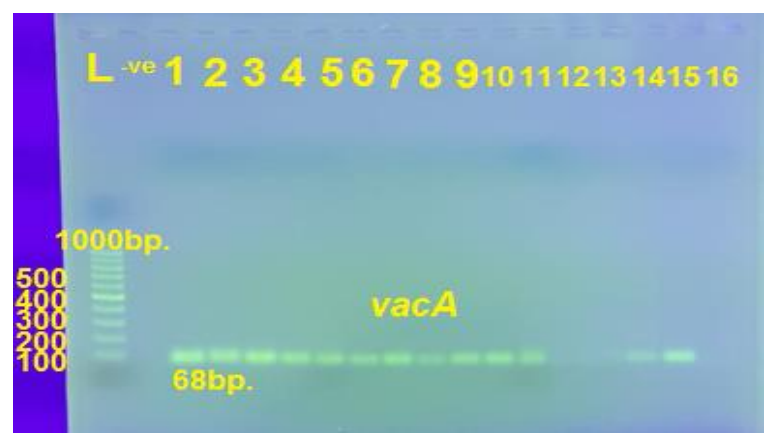

Figure (2): Agarose gel electrophoresis analysis 1\% (stained with safe stain) of PCR products using specific primer (vacA) that showed the expected size 68 bp. Lane L: is 100 bp DNA Marker; Lane 2 is (-ve) negative control, Lanes 3-16: samples amplified from $H$. pylori genome run on $75 \mathrm{~V}$ for $45 \mathrm{~min}$. samples number 1 to10, 14 , and 15 were positive for vacA gene, while samples number 12, 13 and 16 were negative.

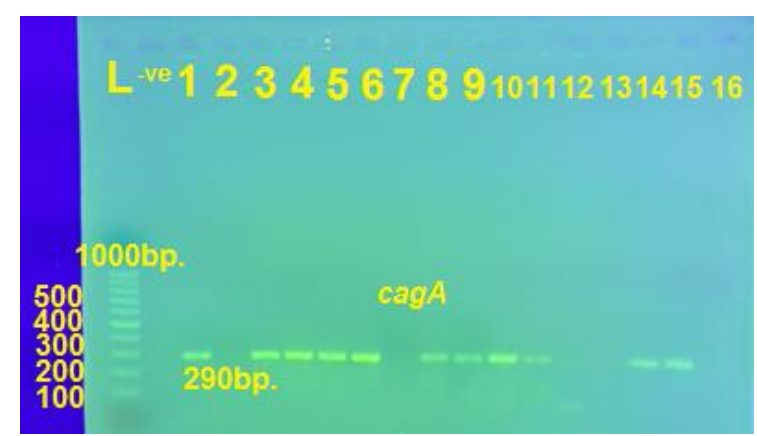

Figure (3): Agarose gel electrophoresis analysis 1\% (stained with safe stain) of PCR products using specific primer (cagA) that showed the expected size 68 bp. Lane L: is 100 bp DNA Marker; Lane 2 is (-ve) negative control, Lanes 3-16: samples amplified from $H$. pylori genome run on $75 \mathrm{~V}$ for $45 \mathrm{~min}$. samples number $1,3,4,5,6$, $8,9,10,11,14$ and 15 were positive for cagA gene, while samples number 2, 7, 12, 13 and 16 were negative. 


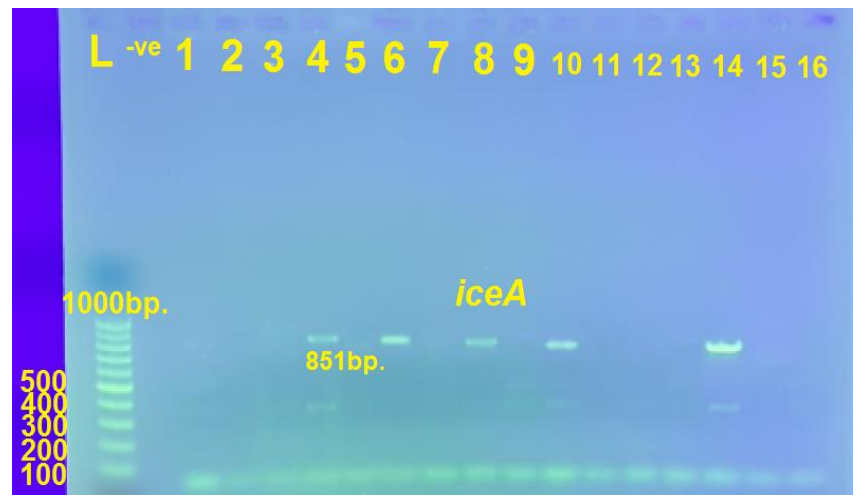

Figure (4): Agarose gel electrophoresis analysis 1\% (stained with safe stain) of PCR products using specific primer (iceA) that showed the expected size 851 bp. Lane L: is 100 bp DNA Marker; Lane 2 is (-ve) negative control, Lanes 3-16: samples amplified from $H$. pylori genome run on $75 \mathrm{~V}$ for $45 \mathrm{~min}$. samples number $4,6,8,10$ and 14 were positive for ice $A$ gene, while samples number 1 , to $3,5,7,9,11$, to 13,15 and 16 were negative.

The overall result of PCR test for detecting genes of virulence factors vacA, cagA, iceA among 44 positive cases approved by PCR were 44 (100\%), 37 (84.1\%), and 15 (34.1\%) respectively as shown in Figure (5).

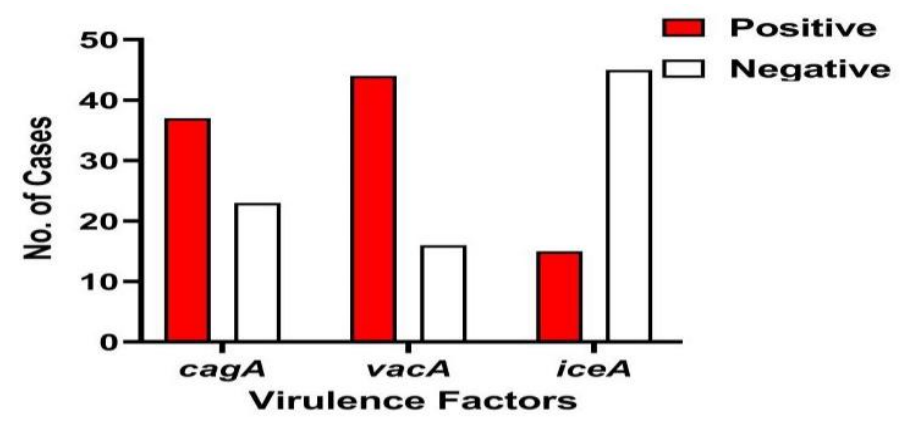

Figure (5): number of $v a c A, \operatorname{cag} A$, iceA genes out of 44 positive PCR cases

\section{Discussion}

The present study included 60 patients in which 44 samples showed positive results for $H$. pylori infection. $21(47.7 \%)$ of them were males and $23(52.3 \%)$ females. Result of statistical analysis showed nonsignificant differences with $(\mathrm{P}<0.56)$ regarding gender of the patients.

Regarding vacA gene, among 44 positive $h$. pylori patients, all patients (100\%) showed positive results for this virulence factor gene. Detecting this gene in all $H$. pylori strains is normal as all H. pylori strains have the gene encode vacA (12). According to a recent study carried out in 2019 in Saudi Arabia, that included samples of gastric biopsies, detected vacA in all included samples with (100\%) frequency, this approves and agree with present study (20). Also, another research carried by Flores- Treviño and his colleagues detected vacA gene in all samples that were 16srRNA positives for $\mathrm{H}$. pylori, which $100 \%$ agree with current study (21). Other researches detected vacA in lower frequencies, for example, Idowu et al. detected vacA with $90.6 \%$ (22), the explanation of such differences belong to investigating subtypes of $v a c A$, unlike present study which used a primer for $v a c A$ gene in general.

The present study detected $\mathrm{CagA}$ gene in $37(84.1 \%)$ out of 44 positive PCR cases. According to a research carried out in 2017, detected cagA in $77 \%$ of the samples which somehow agree whit the present study (23). In an approach to detect prevalence of cagA in Kurdistan region, (24) and his colleagues in 2013 detected cagA with (72\%) frequency. Another research carried by (25) detected cagA with $(72 \%)$ frequency, having such differences in frequency of $c a g A$ will be clear considering geographical distribution of these researches which has an impact on the types of H. pylori strains (26).

The last virulence factor gene IceA, detected in 15 (34.1\%) among 44 positive cases. Results of (20) for detection of iceA gene with approximately same frequencies agree with results of present study. 
Another research carried out in Egypt, detected iceA with (38.8\%) frequency that agree with the present study (27). Detecting iceA gene in lower frequencies than vacA and cagA may be due to the source of clinical isolates, as vacA and cagA are more contributed to gastric disease than iceA, also ice A, is found to be independent of cagA and $\operatorname{vacA}(6)$.

Finally, the studied genes of virulence factors in the present study showed agreement and differences with other studies. Several factors play role in differences like; geographical distribution, sample size, time of sampling and source of the clinical samples .Generally, genotyping of $H$. pylori strains obtained from multiple human populations around the world has demonstrated that the genetic diversity of this bacterium reflects human migrations and subsequent geographic and ethnic separation between human groups (28).

\section{Conclusion}

It can be concluded that genes of virulent factors showed variability and different frequencies among $H$. pylori. Some virulence factors present in all strain of the bacterium while other not. The frequency of the virulence factors depend on its biological functions. Geographical distribution also plays an important role in the distribution of those virulence factors.

\section{References}

1. Krzyżek P, Gościniak G. Morphology of Helicobacter pylori as a result of peptidoglycan and cytoskeleton rearrangements. Prz Gastroenterol. (2018); 13(3): 182-195.

2. Sastry AS, K SB. Essentials of Medical Microbiology: Jaypee Brothers,Medical Publishers Pvt. Limited. (2018).

3. Hooi JKY, Lai WY, Ng WK, Suen MMY, Underwood FE, Tanyingoh D, et al. Global Prevalence of Helicobacter pylori Infection: Systematic Review and Meta-Analysis. Gastroenterology. (2017);153(2): 420429.

4. Bennett JE, Dolin R, Blaser MJ. Mandell, Douglas, and Bennett's Principles and Practice of Infectious Diseases E-Book: Elsevier Health Sciences. (2019).

5. jejo d, Hawezy A. Evaluation of antibacterial activity of Pisticia atlantica kurdica on Helicobacter pylori in Erbil city. (2018).

6. Abu-Taleb AMF, Abdelattef RS, Abdel-Hady AA, Omran FH, El-korashi LA, Abdel-aziz El-hady H, et al. Prevalence of $\langle\mathrm{i}>$ Helicobacter pylori $\operatorname{cag} \mathrm{A}</ \mathrm{i}>$ and $<\mathrm{i}>\mathrm{ice} \mathrm{A}</ \mathrm{i}>$ Genes and Their Association with Gastrointestinal Diseases. Int J Microbiol. (2018); 4809093.

7. Beneduce L, Spano G, Nabi DA, Terzi V, Fiocco D, Massa S. Assessment of a quantitative PCR method for the detection of Helicobacter pylori in environmental samples. Fresenius Environmental Bulletin. (2007); 16: 749-755.

8. Backert S, Yamaoka Y. Helicobacter pylori Research: From Bench to Bedside: Springer Japan. (2016).

9. Chang W-L, Yeh Y-C, Sheu B-S. The impacts of H. pylori virulence factors on the development of gastroduodenal diseases. J Biomed Sci 25, 68 (2018).

10. Subsomwong $\mathrm{P}$, Miftahussurur M, Uchida T, Vilaichone R-K, Ratanachu-Ek T, Mahachai V, et al. Prevalence, risk factors, and virulence genes of Helicobacter pylori among dyspeptic patients in two different gastric cancer risk regions of Thailand. PLoS One. (2017); 12: 1-20.

11. Šterbenc A, Jarc E, Poljak M, Homan M. Helicobacter pylori virulence genes. World J Gastroenterol. (2019); 25(33): 4870-4884.

12. Kabamba ET, Tuan VP, Yamaoka Y. Genetic populations and virulence factors of Helicobacter pylori. Infect Genet Evol. (2018); 60: 109-116. 
13. Jabbar N. Effect of H.pylori and Cag-A on the infertility among males. International Journal of Bioassays 6.03 (2017): 5292-5296.

14. Ansari S, Yamaoka Y. Helicobacter pylori Virulence Factors Exploiting Gastric Colonization and its Pathogenicity. (2019); 11: 11.

15. Casarotto M, Pratesi C, Bidoli E, Maiero S, Magris R, Steffan A, et al. Differential Helicobacter pylori Plasticity in the Gastric Niche of Subjects at Increased Gastric Cancer Risk. Pathogens. (2019); 8(2): 65.

16. Miftahussurur M, Yamaoka Y. Helicobacter pylori virulence genes and host genetic polymorphisms as risk factors for peptic ulcer disease. Expert Rev Gastroenterol Hepatol. (2015); 9(12):1535-1547.

17. Hasan AN, Al-Attar MS. Molecular investigations of $\beta$-thalassemic children in Erbil governorate. AIP Conference Proceedings. (2017);1888(1): 020025.

18. Abu-Taleb AMF, Abdelattef RS, Abdel-Hady AA, Omran FH, El-Korashi LA, Abdel-Aziz El-Hady H, et al. Prevalence of Helicobacter pylori cagA and iceA Genes and Their Association with Gastrointestinal Diseases. Int J Microbiol. (2018); 4809093.

19. Essawi T, Hammoudeh W, Sabri I, Sweidan W, Farraj MA. Determination of Helicobacter pylori Virulence Genes in Gastric Biopsies by PCR. ISRN Gastroenterology. (2013): 606258.

20. Akeel M, Shehata A, Elhafey A, Elmakki E, Aboshouk T, Ageely H, et al. Helicobacter pylori vacA, cagA and iceA genotypes in dyspeptic patients from southwestern region, Saudi Arabia: distribution and association with clinical outcomes and histopathological changes. BMC Gastroenterol. (2019); 19(1): 16.

21. Flores-Treviño CE, Urrutia-Baca VH, Gómez-Flores R, De La Garza-Ramos MA, Sánchez-Chaparro MM, Garza-Elizondo MA. Molecular detection of Helicobacter pylori based on the presence of cagA and vacA virulence genes in dental plaque from patients with periodontitis. J Dent Sci. (2019); 14(2): 163-170.

22. Idowu A, Mzukwa A, Harrison U, Palamides P, Haas R, Mbao M, et al. Detection of Helicobacter pylori and its virulence genes ( $\operatorname{cag} \mathrm{A}$, dupA, and vacA) among patients with gastroduodenal diseases in Chris Hani Baragwanath Academic Hospital, South Africa. BMC Gastroenterology. (2019); 19(1): 73.

23. Dadashzadeh K, Peppelenbosch MP, Adamu AI. Helicobacter pylori Pathogenicity Factors Related to Gastric Cancer. Can J Gastroenterol Hepatol. (2017); 7942489.

24. Salih AM, Goreal A, Hussein NR, Abdullah SM, Hawrami K, Assafi M. The distribution of cagA and dupA genes in Helicobacter pylori strains in Kurdistan region, northern Iraq. Ann Saudi Med. (2013); 33(3): 290-293.

25. Hamad A, Shamran H, Al-Maliki J, Mahmood I. Molecular characteristics and clinical relevance of cytotoxin-associated genes $\mathrm{A}$ and $\mathrm{E}$ of $\langle\mathrm{i}>$ Helicobacter pylori $</ \mathrm{i}>$ from Patients with gastric diseases. Medical Journal of Babylon. (2019); 16(2): 156-162.

26. Ofori EG, Adinortey CA, Bockarie AS, Kyei F, Tagoe EA, Adinortey MB. Helicobacter pylori Infection, Virulence Genes' Distribution and Accompanying Clinical Outcomes: The West Africa Situation. BioMed research international. (2019);7312908.

27. El-Shenawy A, Diab M, Shemis M, El-Ghannam M, Salem D, Abdelnasser M, et al. Detection of Helicobacter pylori vacA, cagA and iceA1 virulence genes associated with gastric diseases in Egyptian patients. Egyptian Journal of Medical Human Genetics. (2017); 18(4): 365-371.

28. Correa P, Piazuelo MB. The gastric precancerous cascade. Journal of digestive diseases. (2012); 13(1): 2-9. 
